\title{
Label-free cell separation and sorting in microfluidic systems
}

\author{
Daniel R. Gossett • Westbrook M. Weaver • Albert J. Mach • Soojung Claire Hur • \\ Henry Tat Kwong Tse • Wonhee Lee • Hamed Amini • Dino Di Carlo
}

Received: 30 January 2010 / Revised: 2 April 2010 /Accepted: 3 April 2010 / Published online: 25 April 2010

(C) The Author(s) 2010. This article is published with open access at Springerlink.com

\begin{abstract}
Cell separation and sorting are essential steps in cell biology research and in many diagnostic and therapeutic methods. Recently, there has been interest in methods which avoid the use of biochemical labels; numerous intrinsic biomarkers have been explored to identify cells including size, electrical polarizability, and hydrodynamic properties. This review highlights microfluidic techniques used for label-free discrimination and fractionation of cell populations. Microfluidic systems have been adopted to precisely handle single cells and interface with other tools for biochemical analysis. We analyzed many of these techniques, detailing their mode of separation, while concentrating on recent developments and evaluating their prospects for application. Furthermore, this was done from a perspective where inertial effects are considered important and general performance metrics were proposed which would ease comparison of reported technologies. Lastly, we assess the current state of these technologies and suggest directions which may make them more accessible.
\end{abstract}

D. R. Gossett • W. M. Weaver • A. J. Mach • H. T. K. Tse •

W. Lee $\cdot$ H. Amini $\cdot$ D. Di Carlo $(\bowtie)$

Department of Bioengineering,

University of California Los Angeles,

420 Westwood Plaza, 5121 Engineering V, Box 951600,

Los Angeles, CA 90095-1600, USA

e-mail: dicarlo@ucla.edu

D. R. Gossett - W. M. Weaver - A. J. Mach - S. C. Hur •

H. T. K. Tse $\cdot$ W. Lee $\cdot$ H. Amini $\cdot$ D. Di Carlo

California NanoSystems Institute,

Los Angeles, CA 90095, USA

S. C. Hur

Mechanical and Aerospace Engineering Department,

University of California Los Angeles,

Los Angeles, CA 90095, USA
Keywords Bioanalytical methods · Cell systems .

Single cell analysis · Biochips · High-throughput screening ·

Microfluidics · Microfabrication · Separations ·

Instrumentation $\cdot$ Field-flow fractionation

\section{Introduction}

The separation and sorting of cells are critical in a variety of biomedical applications including (i) diagnostics, (ii) therapeutics, and (iii) cell biology. Samples of interest are often heterogeneous populations of cells in culture or that comprise a tissue. Blood, for example, is an extremely information-rich, easily accessible tissue. However, it is a complex blend of cells from which isolation of a limited few is necessary for accurate analysis. Although there are challenges, many standard techniques have been developed for cell sorting. These techniques are often labor intensive or require multiple additional "tags" or "labels" to identify cells. Recently, there has been interest in using techniques that take advantage of similar scales of microscale technologies and intrinsic properties of cells for increased automation and decreased cost. It is this area with the potential for improved, cost-effective biomedicine that we focus discussion on here.

Diagnostics The development of miniaturized, point-ofcare diagnostic tests may be enabled by chip-based technologies for cell separation and sorting. Many current diagnostic tests depend on fractionated blood components: plasma, red blood cells, white blood cells, and platelets. Clean, cell-free plasma is necessary for early cancer detection via blood-borne cancer biomarkers [1, 2]. Reticulocytes and mononucleated red blood cells are markers for diseases associated with abnormal red blood 
cell turnover [3]. White blood cells (WBCs), or leukocytes, are required for several hematological tests as well as DNA sequencing. Toner and Irimia's thorough review of bloodon-a-chip technology presents the challenges of handling blood on a chip and the components of blood [4]. A number of rare cells may also be found in blood. For example, circulating tumor cells (CTCs) may be useful for stratifying cancer patients and following up on a course of treatment noninvasively [5]. However, there lacks a consensus on the biochemical markers for these cells, thus label-free techniques are desirable. Fetal cells are also present in limited quantities in the maternal circulation or cord blood. These can be used in noninvasive prenatal diagnostics [6].

Therapeutics Beyond diagnostics, blood components are used in therapeutics. Purified platelets are often transfused during surgery [7]. Stem and progenitor cells from tissue niches may be found in many clinical samples. Enzymedigested adipose tissue is one sample from which autologous donor cells may be derived. There is great interest in using these cells for tissue engineering and disease treatment. A more accessible source of multipotent cells is the amniotic fluid. There is also interest in enrichment of malaria-infected cells, blood cleansing (the removal of bacteria from blood before returning the blood to its donor), and filtering out CTCs to prevent cancer spread.

Cell biology Understanding cell behavior often requires isolation of cell subpopulations to reduce heterogeneity in the studied sample, such as stem cells, CTCs, cancer stem cells, and white blood cell subpopulations. Current methods of isolating stem cells for studying developmental biology involve the use of biochemical markers. These markers may not be available for a specific population. Furthermore, the available markers may not be evidence of cells in a primitive state, and the use of labels may interfere with differentiation and their expansion in vitro or in vivo as well as adding difficulty and cost to the procedure [8]. Thus, label-free sorting methods with minimal handling are desired. CTCs and cancer stem cells are also interesting to biologists. The relation of cell cycle synchrony to cancer is another study for which sorting techniques would be of use [9]. Lastly, extracting precise information about subpopulations in a sample is a ubiquitous goal [10].

Conventional cell sorting strategies Some of the most powerful conventional cell separation strategies are derived from continuous flow cytometry techniques and rely on external labels to distinguish between cell types. Since its invention in the 1960s, flow cytometry has been invaluable to the fields of biology and medicine. A fluidic system with a sheath flow delivers a single stream of sample cells to an interrogation point; high-throughput data are obtained about the cell population by detection of fluorophore-conjugated antibodies. Modern flow cytometers offer sample rates of upwards of 50,000 cells/s and multichannel detector analysis. A useful reference on flow cytometry was written by Shapiro [11].

Fluorescence-activated cell sorting (FACS) is an active sorting method which utilizes complementary fluorophoreconjugated antibodies to label cells of interests. Collected scatter and fluorescence data can be used to identify cell type or gene expression via immunophenotyping, ploidy analysis, size measurement, and fluorochrome expression analysis. This analysis provides a rich data set for discerning subpopulations in a heterogeneous cell population. Along with data acquisition, FACS systems are often used to rapidly sort cells based on their signatures. Current commercial systems allow up to four-way sorting based on fluorescent emission with a throughput of $\sim 30,000$ cells/s.

Magnetic-activated cell sorting (MACS) is a commonly used passive separation technique. MACS employs antibody-conjugated, magnetic beads to bind specific proteins on cells of interest [12]. This immuno-magnetic separation is driven by an external magnetic field, which imparts a force on tagged cells directing them to a collector. When coupled to a flow cytometry system, this technique provides additional information about the separated cells. Miltenyi Biotec GmbH (Bergisch Gladbach, Germany) has commercialized a wide variety of extraction kits for isolation of leukocyte subsets, blood progenitors, circulating tumor cells, endothelial cells, and other cell types. Furthermore, a product for isolation of CD34+ hematopoietic progenitor cells with a high purity for autologous transplantation, CliniMACS, has been commercialized by Miltenyi and approved for clinical use in Europe [13]. Previous work using MACS has shown enrichment is possible of extremely rare cells from large background populations and demonstrated its potential application for circulating tumor cell diagnostics $[14,15]$. The commercially available CellSearch system (Veridex, LLC) has been used for continuous monitoring of CTCs from whole blood in patients with metastatic cancers [5].

Although FACS and MACS offer high-throughput screening with rich data outputs, several factors prevent their wide adoption in clinical settings. In clinical diagnosis the complexity of these systems requires user specialization and training in accordance with the Clinical Laboratory Improvement Amendments (CLIA) in the USA, ensuring high-quality standards of accuracy, reliability, and timeliness. In addition, high initial costs of such systems (US $\$ 250,000$ ), along with operating and reagent costs such as labeling antibodies, magnetic nanoparticles, and sheathfluids, limit their broader adoption as cost-effective approaches. Furthermore, fluid shear stresses in some 
devices and the use of fluorophores and antibodies may affect cell fate and function [16].

Centrifugation is a common macroscale technique for the fractionation of whole blood for clinical and research applications. Separation is based on the differential densities of the cellular components of blood. Erythrocytes with the highest cellular density form a pellet, topped by leukocytes and platelets and then the blood plasma in the supernatant. Further separation of leukocyte subpopulations from the "buffy coat" is achieved by exchanging the suspension medium to match the neutral buoyancy for cell types of interest, prior to re-centrifuging. Density gradients are commonly achieved by dissolving Ficoll in solution for finer extraction of leukocyte populations [17]. One factor that limits centrifugation is that leukocytes are naturally highly sensitive and reactive to changes in the environment and therefore centrifugation may alter their immunophenotype $[18,19]$. Also, centrifugation of whole blood often requires milliliters of volume. Another enrichment protocol involves selective lysis; these techniques, which usually lyse red blood cells, may permeabilize white blood cells and affect surface marker expression [20]. Furthermore, these manual, macroscale, multistep techniques may introduce bias and contamination and require laboratories dedicated to these functions [21]. New methods of isolation are needed to provide native unaltered samples for study.

Label-free, microfluidic strategies In order to satisfy a number of separation and sorting requirements laid out in the previous sections, a number of label-free microfluidic platforms have been developed. Label-free techniques operate by manipulating physical biomarkers to sort cells, that is, where the separation force is dependent on differences in an intrinsic physical property of the cells to be separated. The advent of many of the methods discussed in this review has involved the identification of nontraditional biomarkers. For example, while FACS and MACS depend on molecular interactions chosen due to their specificity to types of cells, "label-free" techniques rely on other distinguishing characteristics of a population of cells. Some proposed markers include cell size, shape, electrical polarizability, electrical impedance, density, deformability, magnetic susceptibility, and hydrodynamic properties. Furthermore, to separate a cell type from a population these biomarkers must be tied to some sort of separation force or fractionation method. The scale of microfluidic systems provides an interface for manipulating single cells and accessing these forces in a variety of ways, including for kinetic, equilibrium, and elution separation (Fig. 1a-c). They also may reduce reagent volume and cost and are potentially portable [22]. There have been many physical and practical challenges in developing technologies that possess the same robustness as conventional systems. Non- intuitive fluid physics govern the microfluidic scale [23]. Flow in microfluidic devices is usually laminar; the Reynolds number, the ratio of inertial to viscous forces, is low, meaning inertial effects are usually considered negligible. Cells entrained in this flow are usually expected to follow fluidic streamlines unless deflected by an external force or restricted by an obstacle. This understanding is now starting to change, with the observation of even more non-intuitive behavior for cells in these flows.
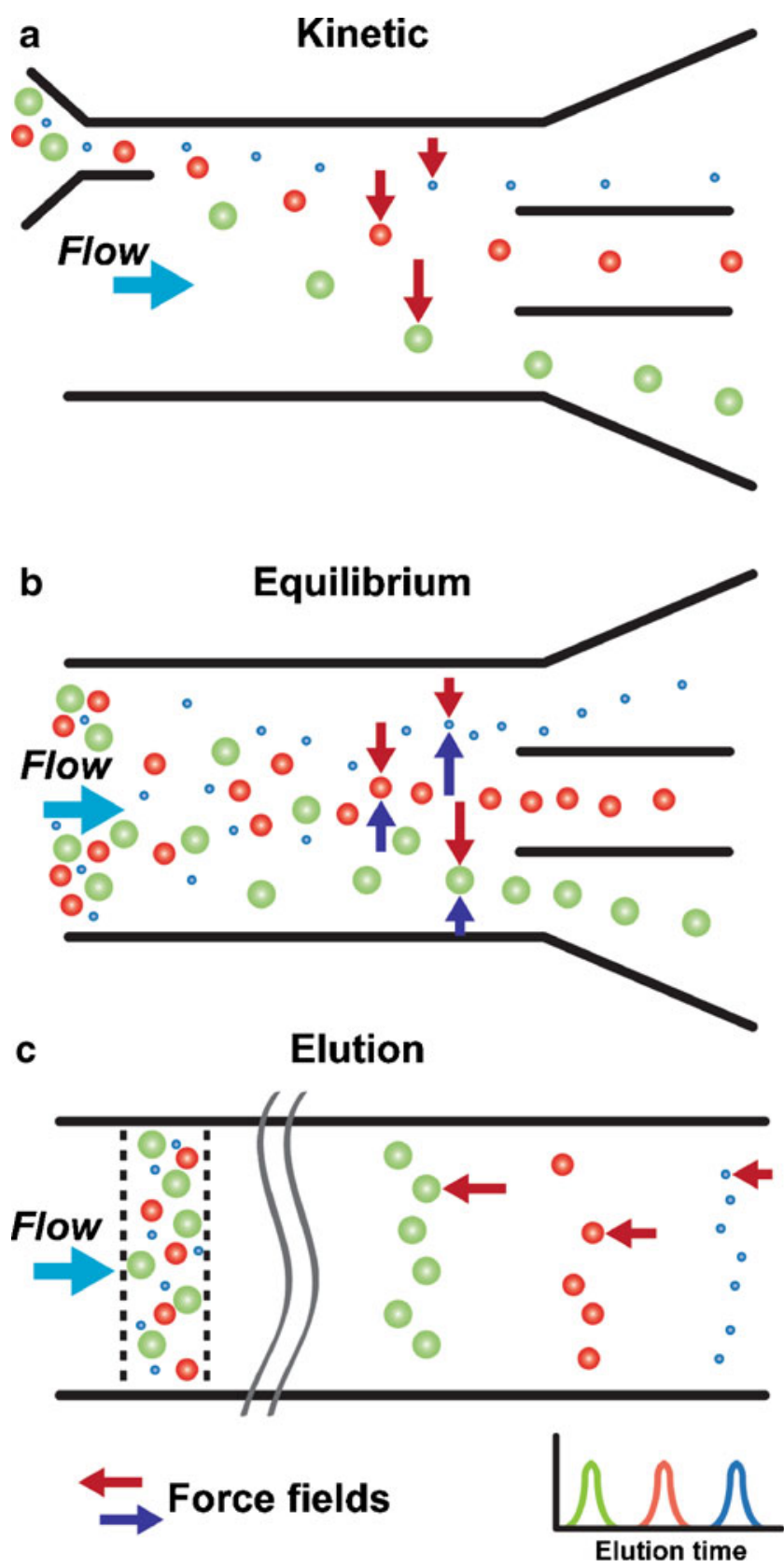

Fig. 1 Generalized separation methods. a Continuous kinetic methods depend on the rate of cell deflection perpendicular to primary channel flow. b Continuous equilibrium methods involve migration to property-dependent equilibrium positions. c Elution methods depend on forces antiparallel to primary flow to create differential retention 
There have been several informative, recent reviews discussing microfluidic cell separation techniques [24-27]. Here we address cell sorting from a new perspective in which inertia is considered important. We also focus discussion on label-free sorting strategies and the important intrinsic cellular biomarkers that have been recently identified. Although data are often hard to come by, we also attempt to directly compare published techniques on several performance measures to provide guidance to a reader interested in and implementing these techniques.

Separation performance metrics Defining metrics will help one to explore the practical trade-offs, for example, throughput versus purity. Units of throughput are highly variable and the most useful value varies depending on the application. Typically, a volumetric flow rate is involved. To account for sample dilution or preprocessing, the volumetric flow rate is multiplied by a volume fraction or a cell density. Commonly, the number of cells sorted per time is reported. This is important as the concentration of cells may affect or limit a number of techniques. Yield or recovery rate is often reported to describe losses of cells either to lysis or retention within the device or tubing. This is reported as a percentage of the original cells remaining in all outputs. Separation criterion is the intrinsic property of the cell that is the basis for its separation. Separation resolution depends on the separation criterion. For sizebased separation the resolution will be the difference in cell diameter that the device can distinguish and effectively eliminate more than $90 \%$ of undesired cells. Separation based on polarizability, acoustophoretic, or other properties may also have quantifiable resolutions, but it is also common practice to report the specific cell types that have been resolved when the technique has been tuned to a specific task. Enrichment of a single component from a sample is often reported. We suggest a more standardized enrichment ratio which is a ratio of selected or desired cells to unselected cells in a particular output channel or reservoir divided by the same ratio in the inlet. Purity or separation efficiency is a commonly reported value that may vary significantly based on definition. It involves the number of contaminant or unselected cells remaining in the fraction that contains the selected cells.

\section{Techniques}

We address a broad range of techniques to accomplish cell separation and sorting. First, we will cover the purely physical separation achieved by the use of microscale filters. Next, we deal with a number of techniques that manipulate microscale fluid dynamics, including hydrody- namic filtration, field-flow fractionation, flow due to microscale structures, and inertial microfluidics. We briefly cover attempts at separation by sedimentation and mimicking phenomena of the microvasculature. We go on to describe the adaptation of aqueous two-phase systems to continuous microfluidics and detail the field-based techniques of magnetophoresis, acoustophoresis, and dielectrophoresis. Lastly, we discuss a number of optical techniques. The separation criteria are listed in the section headings, and an outlook for each technique may be found at the end of each section. Table 1 summarizes these techniques and lists performance metrics.

\section{Microscale filters (size, deformability)}

A commonly employed label-free separation criterion is size. An intuitive approach for separating cells based on size exclusion is by filtration. In the macroscale, fibrous membrane filters are inherently comprised of wide ranges of pore sizes. For applications including fractionating blood into red blood cells, white blood cells, platelets, and plasma, this technique results in low separation efficiency. Microfabricated filter designs are more compatible with blood sample preparation as pore size can be precisely controlled. Four types of microfilters have been reported: weir, pillar, cross-flow, and membrane; and these have all been experimentally validated by $\mathrm{Ji}$ et al. [28]. Weir-type filtration (Fig. 2a), named after a type of dam, is typically used to produce cell-free plasma for diagnostics. In one implementation, capillary action drives flow through a planar slit that was small enough to exclude the cellular components of blood. The amount of plasma produced by this device is limited to several nanoliters due to the method of driving flow $[29,30]$. Continuous flow weir-type filters were developed to process larger blood volumes [31, 32]. Pillar-type (Fig. 2b) filtration employs microposts spaced apart to create critical size cutoffs. This design is usually avoided since cells are trapped in the direction of flow, leading to fouling or clogging. However, Mohamed et al. isolated fetal nucleated red blood cells (fNRBCs) from maternal cells in cord blood with this design [33]. A density separation and dilution step prepared a sample of adult white blood cells and fNRBCs. This suspension was pulled through a pillar array with gradually decreasing space between posts. Adult WBCs were retained by gaps of 2.5 by $5.0 \mu \mathrm{m}$ while smaller, more deformable fNRBCs squeezed through. Amic AB (Uppsala, Sweden) has developed a chip with an injection molded micropillar array for the dual-purpose of driving flow by capillary action and size-exclusion filtering of cells to limit effects in subsequent immunoassays [34]. Cross-flow filtration (Fig. 2c) operates under similar size-exclusion precepts, but flow is perpendicular to the micropost array or weir 


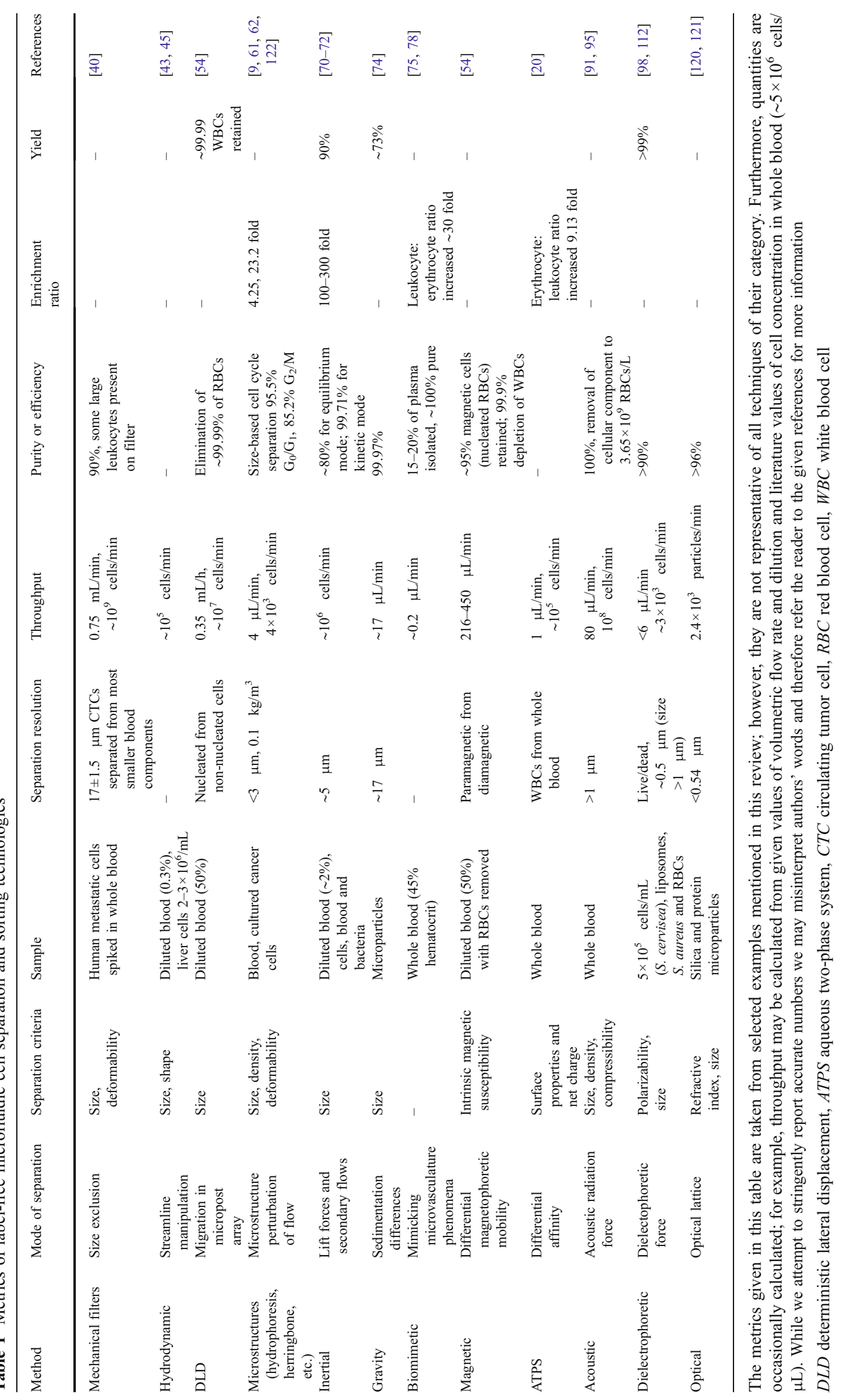



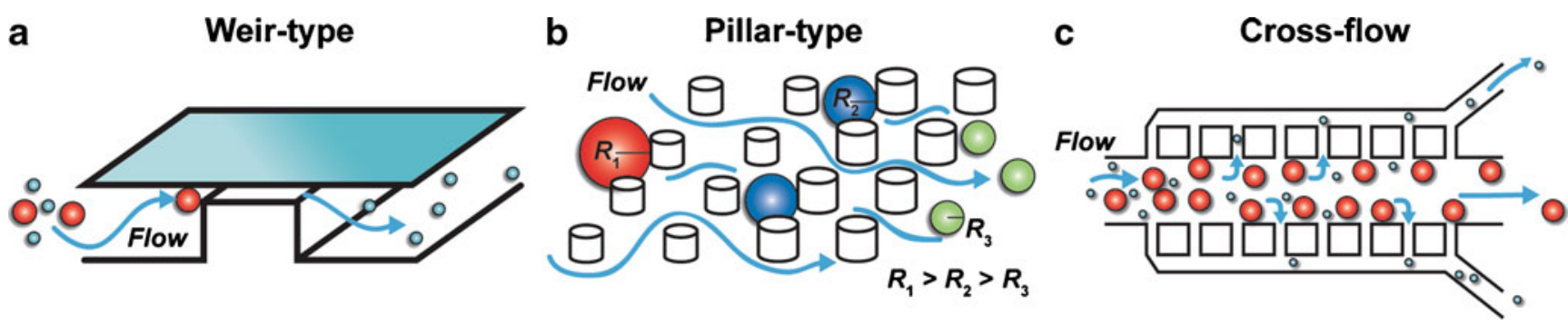

Fig. 2 Microscale filter designs. a Weir-type filters size-exclude cellular components while allowing flow of smaller cells and molecules to pass through a planar slit. b Pillar-type filters are arrays of pillars which exclude cells larger than the spacing of the pillars. c Cross-flow filters are arranged perpendicular to primary channel flow to avoid problems associated with obstructed flow [28] filter. These designs attempt to reduce clogging and counter filter saturation as rejected cells continue in the direction of primary flow while the selected cells continue to a separate outlet. This method has been used for separating plasma from whole blood [30, 32, 35], WBCs from whole blood $[36,37]$, and neonatal rat cardiac cell populations from whole blood [38]. The gap size is manipulated to create a critical size cutoff. This type of filter has been integrated with other components for cell lysis and DNA purification [39]. Membrane filters are comprised of well-defined pores, designed to restrict passage to cells below a critical size. Similar to other types of filtration, high concentrations of particulate matter can lead to clogging [28]. Membrane microfilters have been used to isolate spiked cancer cells in blood and have been integrated with electrolysis for genomic analysis with a high throughput of $7.5 \mathrm{~mL}$ within 10 min and with an efficiency of almost 90\% [40]. This was achieved by fabricating massive arrays of circular or ovular pores. The microscale filter is an uncomplicated method for separating cells based on a biomarker of size or deformability. Ji et al. [28] evaluated all four genres of microscale filters, focusing on the separation of WBCs from RBCs. They demonstrated their cross-flow filter had the highest efficiency in trapping WBCs while passing RBCs and concluded that it was most easily integrated into lab-onchip technologies.

Filters for size-based separation face many challenges including heterogeneity of cell sizes within a population, clogging, and fouling. Clogging of pores may result in irregular flow locally. Deformable rare cells such as CTCs may be damaged or lost as these local perturbations create conditions where extrusion through pores occurs, especially as the throughput is increased [41]. The isolation of these larger cells from blood may be more challenging since typical studies require the study of large volumes of blood $(7.5 \mathrm{~mL})$ to provide valid results [5]. However, a robust, microfabricated filter for label-free separation of blood components would seem a practical precursor to blood cell or plasma analysis. The ability to integrate with existing onchip protein analysis platforms for the analysis of microliter volumes of blood in rapid, point-of-care diagnostic tests, especially with the use of capillary-, gravity-, or pressuredriven pumps for loading blood samples, would be useful. Chips satisfying these criteria were developed by Amic AB, which was acquired in 2008 by Johnson and Johnson.

Hydrodynamic filtration (size, shape)

We will discuss hydrodynamic filtration and pinched flow fractionation in the same category due to their similar operating principles. These techniques presume that at a low Reynolds number the center of a particle will follow fluid streamlines. Fluid flow, alone, is used to dictate sizebased sorting, controlling flow rate through one or more inlets, channel geometry, and configuration of outlets for partitioning the flow. Yamada et al. proposed pinched flow fractionation, a purely hydrodynamic method of fractionating a sample by size [42]. The microfluidic device had two inlets: one to deliver the sample and a second to pinch the sample flow and align its particulate content against the wall in a narrow segment of the channel (Fig. 3a). In this segment smaller particles reached streamlines closer to the wall than their large counterparts. The channel then widened, rapidly dispersing particles perpendicular to primary channel flow as they followed the streamline in which they were centered. The widened channel then branched into smaller outlets through which the particle streams were collected. Takagi et al. enriched red blood cells from a blood suspension diluted to $0.3 \%$ [43]. At a sample flow rate of $20 \mu \mathrm{L} / \mathrm{h}$ erthyrocytes predominantly flowed down one outlet; acellular blood components were distributed between that outlet and another containing no erythrocytes. Interestingly, the shape of red blood cells was important and the authors concluded the minimum width of the cell determines its trajectory in the expanding channel. Thus discoid red blood cells and spherical cell components would have disparate trajectories. In this work the fluidic resistance of each outlet was designed to achieve a more effective separation. Hydrodynamic filtration is a similar technique requiring a single sample inlet [44]. The microfluidic device consists of a straight channel with a number of perpendicular branched channels (Fig. 3b). A fraction of 

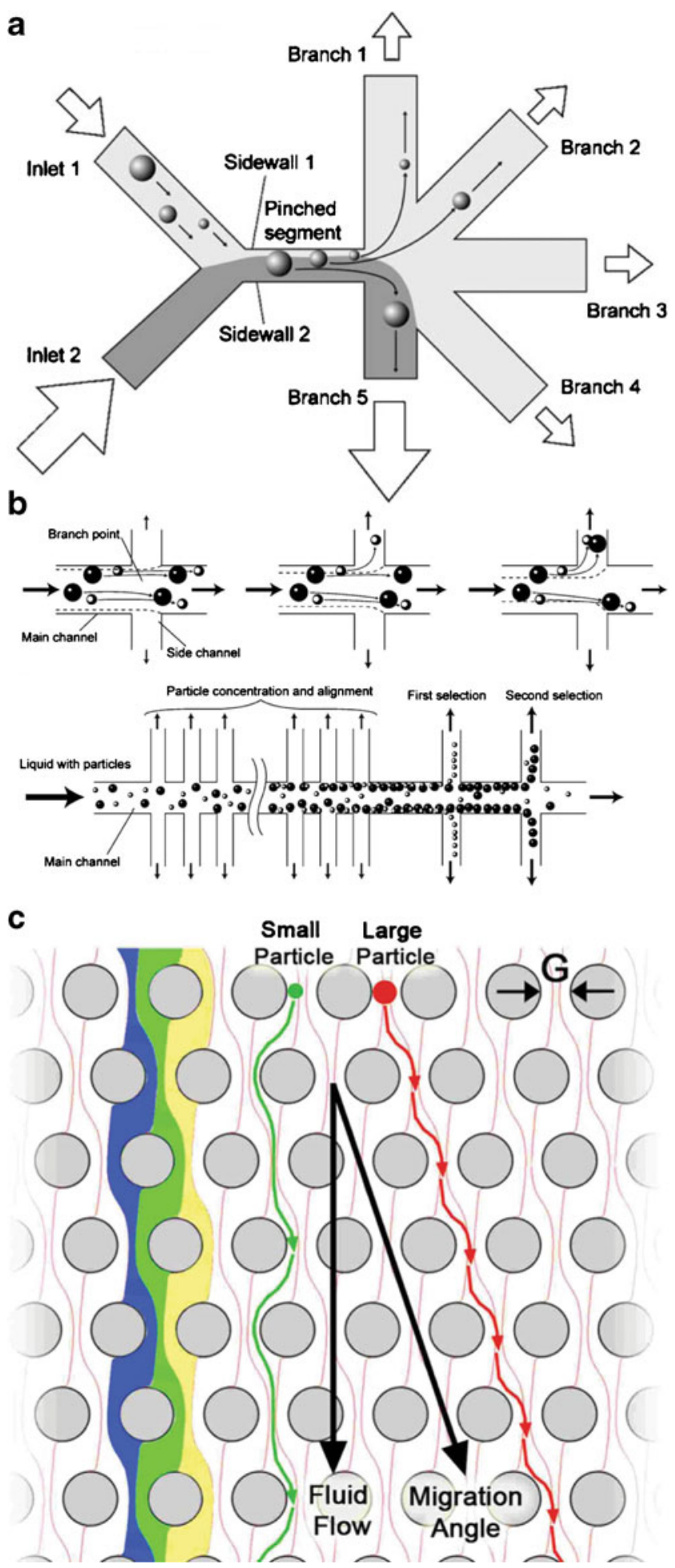

Fig. 3 Hydrodynamic methods of separation include a pinched flow fractionation [43] (reproduced by permission of The Royal Society of Chemistry. http://dx.doi.org/10.1039/b501885d), b hydrodynamic filtration [44] (reproduced by permission of The Royal Society of Chemistry. http://dx.doi.org/10.1039/b509386d), and c deterministic lateral displacement (reprinted with permission from [52]. Copyright 2009, American Institute of Physics) the flow goes down these branches dragging cells closer to the walls as they move downstream. Downstream the flow rate of these branches increases relative to that of the main channel and particles may exit the main channel; smaller particles, located in streamlines closer to the walls, enter at earlier branches than larger particles. Recently, this technique was applied to the separation of two populations of liver cells, exploiting size differences between hepatocytes and nonparenchymal cells [45]. These techniques have not been commercially developed according to our knowledge.

Deterministic lateral displacement (size)

Laminar flow, hydrodynamic particle manipulation has been extended to micropost arrays. These arrays have been used to continuously separate particles by size using a principle known as deterministic lateral displacement (DLD), as the displacement of cells or particles perpendicular to primary flow is determined by the pattern of the array [46]. Particles below a critical size follow streamlines through the array gaps with no net displacement from the original streamline. Particles above the critical size are "bumped" laterally to cross sequential streamlines with each row traveling at an angle predetermined by the post offset distance (Fig. 3c). The critical particle size for fractionation depends on the gap between posts and offset of posts [47]. DLD has been applied to the separation of red blood cells, white blood cells, and platelets [48, 49]. It has a very good size resolution, capable of resolving a 10-nm size difference [46] and has been demonstrated to be effective for cell size measurement [50]. Moreover, this technique has been used to expose cells to a multitude of solutions to carry out lysis, labeling, and washing [51]. Modifications to channel boundaries have been demonstrated to eliminate compromising fluid flow found in these regions [52]. Simulations suggest that DLD throughput could be improved by reducing post arrays to point-like obstacles, thus decreasing fluidic resistance [53]. Commercial development (Artemis Health) suggests promise for the approach as part of a system to isolate nucleated red blood cells from the maternal circulation. DLD eliminates $99.99 \%$ of normal red blood cells, processing $0.35 \mathrm{~mL} / \mathrm{h}$ [54]. DLD techniques may involve a resulting dilution of the sample as particles are separated into coflows; however, they are capable of processing whole blood.

Field-flow fractionation

Field-flow fractionation (FFF) is a body of techniques where a field (flow, electric, gravitational, centrifugal, etc.) acts on particulate matter in a direction perpendicular to primary channel flow. In a microfluidic device, with its characteristic parabolic velocity profile, particles that feel 
the greatest force are driven closest to the wall where flow velocity is lowest and therefore have a long retention time. Particles feeling a weaker perpendicular force remain in faster lamellae of flow and elute quickly. Contrary to many of the techniques presented in this review, field-flow fractionation is an elution technique where differential retention in the microchannel creates separation, as in chromatography techniques, rather than direction down different outlet channels [55]. However, split-flow lateraltransport thin (SPLITT) is a continuous variant of this approach [56]. As the number of fields coupled with FFF is large the selection criteria are wide-ranging: size, shape, density, rigidity, subcellular ultrastructure, etc. As a result of low shear rates and minimal handling of cells FFF techniques typically have high recovery or yield. However, the throughput of the technique is currently low, as low as $10^{6}$ cells in large fractions of an hour. Recently, FFF has been directed at the separation of stem cells from clinical samples. Vykoukal et al. used dielectrophoretic field-flow fractionation (DEP-FFF) to select stem cells from an adipose tissue-derived cell suspension [57]. For further reading on field-flow fractionation, an extensive review of recent trends was written by Roda et al. [58]. Importantly, sedimentation FFF and gravitational SPLITT have been developed commercially for particle separation (Postnova Analytics).

Microstructures: grooves, chevrons, herringbones, and hydrophoresis (size, density, deformability)

Microstructure protrusions planar and lateral to flow have been used for rapid mixing in lab-on-a-chip applications. Flow past static structures creates lateral flow components and flow alteration within the channel that induce mixing $[59,60]$. However, they have also been proven useful for entraining cells and performing size-, deformability-, and density-based cell separation. Several mechanisms for particle separation in these helical flows have been proposed. Geometries have been designed for binary separation of particles of different sizes and for concentrating or focusing all particulate matter to a single stream. The concept of "hydrophoresis" was first introduced to explain particle movement through a microfluidic device containing slanted obstacles at the top and bottom of the channel [61]. Likely, particles are entrained in helical flows and are acted on, differentially, by gravity and sterics (size differences restrict movement around microstructures). These microstructures are capable of precise control of cell distribution within a microchannel enabling the resolution of cells with diameter differences as small as $7.3 \%$ [61]. That is, size differences result in deterministic placement into fluid streamlines in an analysis or collection region. However, these cells were not collected off-chip. Recently, Choi et al. exploited size differences between the $G_{0} / G_{1}$ and $G_{2} / M$ phases to separate human leukemic monocyte lymphoma cells into strategically placed outlets [9]. Herringbone grooves create a flow pattern suitable for segregating similarly sized particles based on density. A density resolution of $0.1 \mathrm{~g} / \mathrm{cm}^{3}$ was demonstrated [62]. While focusing for massively parallel imaging was demonstrated, outlet configurations for actually separating cells or particles in this device were not. As a result of the low throughput of these methods $\left(10^{5}\right.$ cells $\left./ \mathrm{h}\right)$ application areas should not require large processing volumes.

Inertial (size)

We recently reviewed inertial microfluidics and its applications to label-free sorting and direct the reader there for a more complete background [63]. Briefly, in the upper range of flow rates explored in microfluidic systems Reynolds numbers in the range of 1-100 are common. Additionally, a particle Reynolds number, based on the velocity around the particle at the particle length scale, can be on the order of 1 $\left(R e_{\mathrm{P}}=\operatorname{Re} \times(\text { particle dimension/channel dimension })^{2}\right)$. In this range inertial effects become significant, and the assumption that particles follow fluid streamlines leads to incorrect results. For a circular pipe, initially randomly dispersed, suspended particles concentrate to a narrow band at approximately 0.6 times the radius of the pipe due to lift forces acting on the particles [64]. This focusing phenomenon has been described as a balance of two inertial lift forces: (1) the shear gradient lift and (2) the wall effect lift. Furthermore, the number and location of equilibrium positions may be manipulated by controlling channel geometry $[65,66]$. A second inertial effect in microfluidic systems arises in curving channels such as arcs and spirals. Higher momentum fluid at the center of a channel displaces lower momentum fluid near channel walls as it is driven around a curve [67]. This results in counter-rotating vortices perpendicular to primary channel flow which may also influence particle positions [68]. Cells can be entrained in this secondary flow and may be dragged perpendicular to the primary flow.

As in other techniques there can be equilibrium and kinetic inertial separations. For efficient separation based on differential equilibrium positions two conditions must be met: (1) both the selected and unselected particles must be accurately focused, and (2) their equilibrium positions must be different. Inertial lift forces depend on particle size, but equilibrium positions in straight channels are roughly the same for all particle sizes so long as the length of the channel gives sufficient time for particles to migrate to these equilibriums. Creation of distinct equilibrium positions requires an additional, size-dependent force on 
the order of the inertial lift force. The Dean drag force found in spiral or asymmetrically curving channel geometries is such a force. Equilibrium position-based separation was explored for membrane-free filtration, enriching particulate matter in suspension. In these devices suspended particles are driven through a microchannel by a syringe pump. Initially randomly distributed throughout the channel, particles above a critical size migrate to equilibrium positions. Strategically placed outlet channels or bifurcations separate fluid with concentrated particles from fluid with few to no particles [69]. Seo et al. demonstrated this technique, concentrating $10.5-\mu \mathrm{m}$ polystyrene microspheres with greater than $99 \%$ efficiency. This type of enrichment has been replicated in a number of microchannel designs.

The force balance between inertial lift forces and Dean drag forces has been used to enrich platelets by a factor of 100 from whole blood diluted to $2 \%$ in phosphate buffered saline at $0.9 \mathrm{~mL} / \mathrm{min}$ [70]. Kuntaegowdanahalli et al. [71] used a spiral channel design to achieve $90 \%$ efficient separation of three particle sizes $(10,15$, and $20 \mu \mathrm{m})$. The same design was applied to the separation of two neural cell types with average diameters of 8 and $15 \mu \mathrm{m}$. As a result of the heterogeneity of size in these populations, as is present in most biological systems, efficiency was reduced to $80 \%$. The throughput was still high $\left(10^{6}\right.$ cells $\left./ \mathrm{min}\right)$, with an operational flow rate in the milliliters per minute range [71].

Kinetic, inertial separation is possible by utilizing differences in the lateral lift forces as they depend on particle size. Wu et al. [72] took advantage of this dependence to separate E. coli from blood, positioning a blood and $E$. coli suspension near the channel wall with a perpendicular-acting sheath flow. Blood cells felt a larger lift force than bacteria, resulting in significant differences in position within the channel cross section. These cell-laden streams were sorted at 70,000 cells/s by splitting the channel, achieving a 300 -fold enrichment of bacterial cells with more than $99 \%$ purity [72].

Inertial microfluidic separation typically involves a dilution, either prior to injection or within the device, as interparticle interactions lead to defocusing. Furthermore, it is anticipated that increased viscosity, due to large cellular content, would increase the channel length required to achieve focusing. However, this restriction is compensated for by high volumetric flow rates, surpassing most other microfluidic technologies by orders of magnitude. As such, inertial microfluidic separations should be considered for applications which would benefit from the throughput and is being commercially developed for water filtration (Palo Alto Research Center). Lastly, their independence from external force fields eases their integration into massively parallel systems $[65,73]$.
Gravity and sedimentation (size)

Huh et al. demonstrated size-based particle sorting by a gravitational force with hydrodynamic amplification [74]. Unlike the inertial separation described in the previous section, gravitational and sedimentation methods depend on the density of the particle, rather than the density of the fluid. A randomly distributed particle suspension is injected into the device parallel to gravity, and particles are hydrodynamically focused in one dimension by sheath flows. A $90^{\circ}$ turn delivers the focused suspension to a gradually widening separation region. In this region gravity is perpendicular to channel flow, and particles sediment at a velocity, $U_{\text {sed }}$, dependent on their radius, $r$, the acceleration of gravity, $g$, the difference between the density of the particles and the density of the fluid, $\Delta \rho$, and the viscosity of the fluid, $\mu\left(U_{\text {sed }}=2 r^{2} g \Delta \rho / 9 \mu\right)$. Separation of particles with different radii is amplified by hydrodynamic effects: the channel gradually widens asymmetrically such that flow near the bottom of the channel is angled downward, assisting migration of larger radius particles. The technique was demonstrated by separation of polystyrene particles ( 1 and $20 \mu \mathrm{m}$ or 3 and $20 \mu \mathrm{m}$ ) and polydisperse droplets for biomedical applications. This technique was not demonstrated with cells and was limited to a volumetric flow rate of $\sim 1 \mathrm{~mL} / \mathrm{h}$.

\section{Biomimetic}

Biomimetic microfluidic separation techniques emulate hemodynamic phenomena involving the intrinsic properties of blood and the microvasculature to achieve desired fractionation of blood components. These phenomena include plasma skimming, leukocyte margination, and the Zweifach-Fung effect, also known as bifurcation law. Although their mechanisms are not described, these effects have been observed and replicated in microfluidic systems. Within the microvasculature red blood cells tend to be concentrated near the center of the vessel while white blood cells are marginalized to a plasma-rich region at the walls. Bifurcation law describes red blood cell behavior when a microcapillary splits; red blood cells predominantly choose the larger of the daughter capillaries. A number of techniques have been developed to take advantage of these effects. Shevkoplyas et al. [75] developed a method for isolation of white blood cells from whole blood by margination. A water column $\left(\sim 40 \mathrm{cmH}_{2} \mathrm{O}\right)$ was used to drive $\sim 70 \mu \mathrm{L}$ whole blood through multiple symmetric and asymmetric bifurcations, leading to enrichment of white blood cells from 4,300 to $42,300 / \mu \mathrm{L}$ and the ratio of white blood cells to red blood cells changed from 1:1,100 to 1:32. A large majority of red blood cells entered the wider outlet while marginalized leukocytes entered the narrower outlet 
(Fig. 4a). Assuming this effect would be present at all heights within the microchannel, Jaggi et al. extended the channel height and increased throughput to the microliter per minute range [76].

Cell separation from plasma is another common objective. The plasma skimming phenomenon has been exploited in vitro for separation of cell-free plasma. Faivre et al. [77] explored this effect with diluted blood in microfabricated channels. They demonstrated the cell-free layer could be enhanced by a sudden channel expansion. Furthermore, they applied a trifurcating outlet following this sudden expansion to separate plasma in a $16 \%$ hematocrit blood suspension at $200 \mu \mathrm{L} / \mathrm{h}$, isolating $24 \%$ of the initial plasma [77]. Sollier et al. [21] revisited this method recently, demonstrating that the effect is present in wider channels and at higher flow rates. At $100 \mu \mathrm{L} / \mathrm{min}$ and a dilution or $1: 20,10.7 \%$ of plasma was separated with purity similar to that of centrifugation methods [21]. Important parameters include the suspension viscosity (adjusted by dilution), the shape and size of the expansion, and flow rate. At these high flow rates inertial effects may affect the plasma skimming. Bifurcation law was also manipulated to achieve highly efficient plasma separation across a wide range of hematocrits. Successive branches off the main channel remove plasma (Fig. 4b). As a result of the high (>6:1) ratio of main channel flow rate to branch channel flow rate, blood cells continuously pass through the main channel while $15-25 \%$ of the plasma is collected from the branches. The sample flow rate is $10 \mu \mathrm{L} / \mathrm{h}[78]$.

Biomimetic separation, comprised of a number of disparate techniques, may be applied in a number of ways. The operational flow rates of the plasma-skimming devices tested by Faivre et al. and Sollier et al. enable them to process large volumes of sample. We believe this will be most useful in therapeutic applications where donor samples may be large and this throughput (up to $100 \mu \mathrm{L} /$ min) would be advantageous. The devices produced by Shevkoplyas et al. (leukocyte margination) and Yang et al. (bifurcation law) perform at much lower flow rates. This may restrict their utility to lab-on-chip devices where handling of small volumes is required (volumetric flow rate $\sim 10 \mu \mathrm{L} / \mathrm{h})$.

Magnetophoresis (magnetic susceptibility)

Magnetic activated cell sorting is a label-based, continuous, passive separation method. However, there are microfluidic systems which employ the intrinsic magnetophoretic properties of hemoglobin, found in eryrthrocytes, for separation. Unpaired electrons in deoxygenated and methemoglobin make them paramagnetic while these electrons form covalent bonds in oxyhemoglobin making it diamagnetic. Zborowski et al. measured the magnetophoretic mobility of erythrocytes containing these species (under a magnetic field of $1.4 \mathrm{~T}$, mean gradient of $0.131 \mathrm{~T} / \mathrm{mm}$ ) and made a case for separation based on these properties when label-based separation is limited by shared surface antigens [79]. Han and Frazier created several devices for magnetophoretic separation [80-82]. However, the separation force in these systems decayed with distance into flow. Furlani provided a theoretical model of a continuous flow, gravitydriven microfluidic systems for separation of WBCs and deoxygenated RBCs which instead uses an array of softmagnetic elements which are magnetized by a bias field [83]. In this model WBCs behave as diamagnetic microparticles and deoxygenated RBCs are paramagnetic. Therefore, they move in opposite directions perpendicular to primary flow. Complete separation is estimated to occur after $80 \mathrm{~s}$ of transit through the channel, but it is expected that cells will be sufficiently segregated to collect the populations in separate outlets at an earlier time. The proposed device has not been experimentally validated. Syringe pump-driven microdevices for magnetophoretic separation have been demonstrated operating at low flow rates $(20 \mu \mathrm{L} / \mathrm{h}$, flow velocity of $0.1 \mathrm{~mm} / \mathrm{s})$. Inherent in throughput calculations for these devices is a dilution step to chemically prepare deoxygenated hemoglobin red blood cells. Separate outlets contained $93.9 \%$ of red blood cells and $89.2 \%$ of white blood cells [84].

Huang et al. created a multi-module microfluidic system for isolation of nucleated red blood cells (NRBCs) from blood of pregnant women [54]. The first module, as described above, was a DLD microfluidic device for depleting the smaller, non-nucleated red blood cells. This debulking step removed most of the adult RBCs, leaving behind WBCs and NRBCs. Subsequently, a magnetic column, with a magnetic field of $1.4 \mathrm{~T}$, retained the paramagnetic NRBCs while passing 99.90 to $99.99 \%$ of diamagnetic WBCs. As with other techniques, separation efficiency, purity, and throughput were at odds. For the highest efficiency and purity a lower flow rate $(13-27 \mathrm{~mL} /$ h) and multiple cycles were required. The commercial development (Artemis Health) of this technique and its unique application for noninvasive diagnostics suggests promise.

Aqueous two-phase systems (surface properties, net charge)

Aqueous two-phase systems (ATPS) are a technique used for separation of biological materials. Briefly, separation is based on the differential affinity of biological materials for either of two immiscible polymers (usually polyethylene glycol (PEG) or dextran) or their interface. Separation criteria include surface properties and net charge. Salts such as lithium sulfate may be added to change affinity or maintain physiological osmolarity. However, ATPS cell 


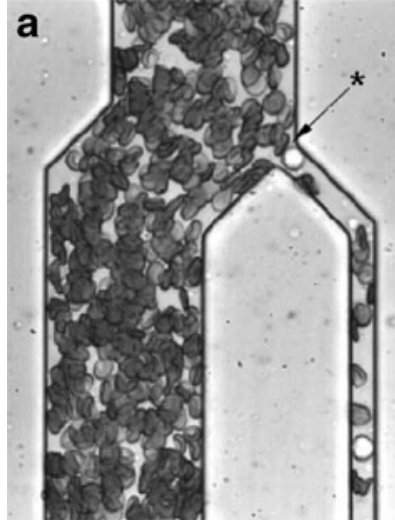

Fig. 4 Microdevices that mimic the microvasculature. a Leukocyte margination is used to isolate leukocytes $\left(^{*}\right)$ as they are typically found in the near-wall regions of flow (reprinted in part with permission from Shevkoplyas et al. [75]. Copyright 2005 American

separation in the macroscale has many drawbacks. These were outlined by SooHoo and Walker: (1) a large volume of sample is required, (2) separation can take up to $20 \mathrm{~min}$, (3) multiple separations may be required, and (4) continuous processing is difficult [20]. Yamada et al. applied ATPS in a continuous microfluidic system to partition plant cell aggregates [85]. Sorting of these large bodies (37 to $96 \mu \mathrm{m})$ was limited by sedimentation or flotation, which occurred faster than partitioning by affinity. Nonspecific migration limited purity to $70 \%$. Microfluidic ATPS can also be used to separate live and dead cells [86].

SooHoo and Walker [20] developed a device for leukocyte enrichment from whole blood by manipulating the differential affinity of white and red blood cells for PEG or dextran phases or their interface. They achieved a 9.13fold enrichment of the erythrocyte to leukocyte ratio [20]. The mechanism for these specific interactions has not been thoroughly evaluated. While microfluidic ATPS improves processing time over macroscale ATPS due to high surface area to volume ratios, throughput is low relative to other microfluidic technologies $\left(<10^{5}\right.$ cells $\left./ \mathrm{min}\right)$. Dilution is limiting and syringe pump fluctuations affecting interface stability or position may limit purity [20]. However, further exploration in this area and better characterization of these systems fill a useful niche where a unique biomarker is required for distinguishing populations.

\section{Acoustophoresis (size, density, compressibility)}

When cells or particles suspended in fluid are exposed to ultrasound of wavelength, $\lambda$, and pressure amplitude, $P_{0}$, they experience an acoustic radiation force, $F_{\text {Acoustic, }}$ described in Eq. 1. Separation of particles utilizing this force can be achieved by generating a standing wave over the cross section of a microfluidic channel (Fig. 5a). In this configuration, while a fluid carries particles through the
Chemical Society). b Bifurcation law is manipulated to remove cellfree plasma from blood [78] (reproduced by permission of The Royal Society of Chemistry. http://dx.doi.org/10.1039/b516401j)

channel, a radiation force pushes particles towards either the pressure nodes or the pressure antinodes of the standing wave. Reviews on the details of the acoustic manipulation of particles can be found elsewhere [87, 88].

$F_{\text {Acoustic }}=-\left(\frac{\pi P_{0}^{2} V_{P} \beta_{f}}{2 \lambda}\right)\left(\frac{5 \rho_{P}-2 \rho_{f}}{2 \rho_{P}+\rho_{f}}-\frac{\beta_{P}}{\beta_{f}}\right) \sin \left(\frac{4 \pi x}{\lambda}\right)$

The strength of the acoustic radiation force depends on three different properties: the volume of the particle $V_{\mathrm{P}}$, the relative density, $\rho$, of particle $(\mathrm{P})$ and fluid (f), and the relative compressibility, $\beta$, of the particle and the fluid. As deduced from Eq. 1, the acoustic force can have the opposite sign for particles with different densities. These particles will be attracted to different parts of the channel: pressure nodes (high density particles) or antinodes (low density particles). In an example of this, Petersson et al. demonstrated separation of red blood cells and lipid microemboli with a separation efficiency greater than $95 \%$ $[89,90]$. RBCs were focused at the center line of the microfluidic channel (node) and lipids were focused near the side walls (antinodes). An even simpler application of the acoustic standing wave is particle focusing for filtration [91-93]. Typically the focused particles, such as blood cells, exit through a centered outlet while clear fluid, or plasma-containing fluid, is collected from other outlets. Recently, this has been demonstrated with whole blood (most previous acoustic separation was performed on samples diluted to $5-10 \%$ by volume) [91].

In principle, similar application of acoustic standing wave separation for particles with different compressibilities is possible. In flow segregation of polymeric particles based on compressibility in a millimeter-scale fluidic device 
a

a

b

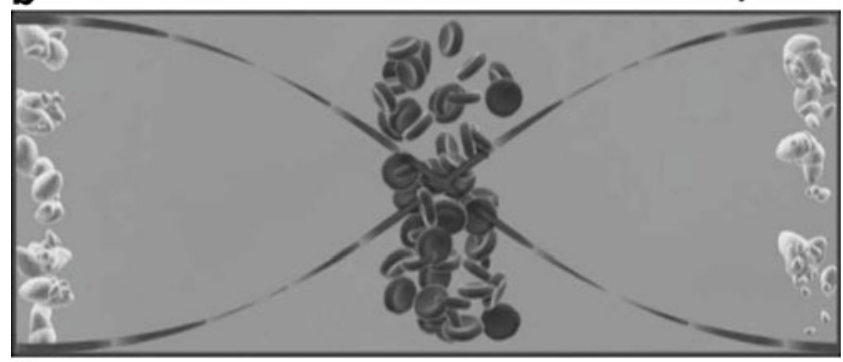

C

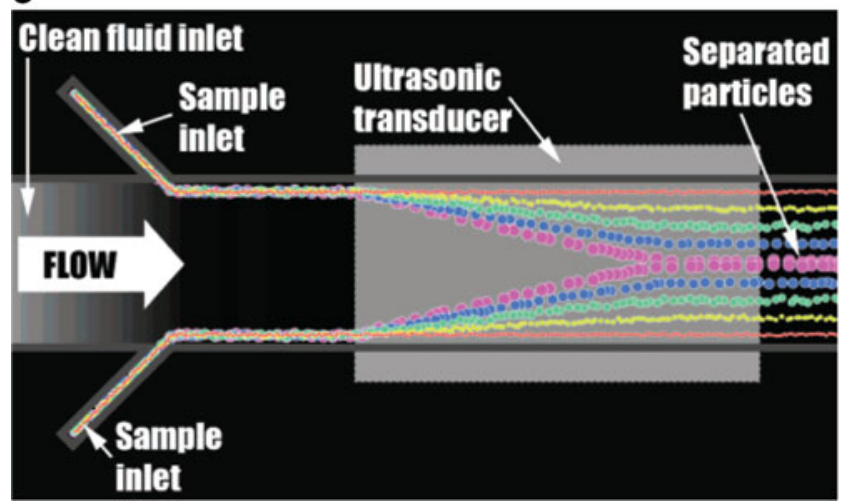

Fig. 5 Acoustic separation. The acoustic radiation force may be manipulated for density-based, equilibrium separation (a, b) [88] (reproduced by permission of The Royal Society of Chemistry. http:// dx.doi.org/10.1039/b601326k), or size-based kinetic separation (c) (reprinted with permission from Petersson et al. [95]. Copyright 2007 American Chemical Society)

has been demonstrated [94]; however, we have not found any report of cell separation based on this. There have been several reports of particle sorting based on size [92, 95]. The techniques that have been covered thus far may be considered equilibrium techniques where the equilibrium positions within a channel vary depending on cell or particle density. On the other hand, size-based acoustic standing wave separation techniques are kinetic. The acoustic radiation force acting on particles with different sizes but the same densities will have the same sign and therefore focus the particles to the same location in the channel. However, the force's magnitude is proportional to the particle volume. If a cell suspension is introduced near the walls of a primary channel and deflected toward the node at the center of a channel particles will cross streamlines at different rates. As shown in Fig. 5b centered outlets remove particles pushed by a larger force while smaller particles flow out of outlets at the edges. This mode of separation has a resolution greater than $1 \mu \mathrm{m}$ with a range of separation efficiencies depending on the application.

Acoustic separation is being explored commercially for the binary separation of red blood cells and lipids (ErySave $\mathrm{AB}$, Sweden). This separation is expected to be used during surgery in adipose tissue where fat particles may cause complications. Other methods that perform the same function have numerous drawbacks which do not apply to this technology [89].

Dielectrophoresis (polarizability, size)

The ability of electric fields to impart forces on particles has been used as a means of manipulation both in standalone separation devices, and as modules in micro total analysis systems ( $\mu \mathrm{TAS}$ ). Dielectrophoresis (DEP), the basis for this microscale manipulation, relies on the underlying principle of electrokinetics. When polarizable molecules such as those in polymer beads, large biomolecules, and cells are placed in a non-uniform electric field, the field can impart a net force on the particle due to an induced or permanent dipole. DEP has been applied in a number of systems based on selective particle trapping and elution or deflection in continuous flow (Fig. 6). The balance between fluid drag and the DEP force is critical. The equation for the force acing on a particle of finite volume and polarizability in an electric field can be seen in Eq. 2. Both the real, $\operatorname{Re}\left[f_{\mathrm{CM}}\right]$, and the imaginary, $\operatorname{Im}\left[f_{\mathrm{CM}}\right]$, components of the Clausius-Mossotti $(\mathrm{CM})$ factor, $f_{\mathrm{CM}}$, directly and independently, affect the force, where force scales with the cube of the length (radius, $r$, or diameter) of the particle [96].

$F(\omega)=2 \pi \varepsilon_{m} r^{3}\left(\operatorname{Re}\left[f_{C M}\right] \nabla E_{R M S}^{2}-\frac{2 \pi}{\lambda} \operatorname{Im}\left[f_{C M}\right] E_{R M S}^{2}\right)$

Dielectrophoretic forces can arise in an electric field generated with either DC or AC currents. Use of the latter reveals an interesting component of the electric field force lying within the frequency-dependent $\mathrm{CM}$ factor. The $\mathrm{CM}$ factor represents the frequency-dependent dielectric properties of both the particle and the surrounding medium. Specifically, the CM factor depends upon the frequency and complex permittivity of both the particle and the surrounding medium $\varepsilon_{p}^{*}(\omega)$ and $\varepsilon_{m}^{*}(\omega)$ [97]. The equation for the $\mathrm{CM}$ factor, as well as those for the complex permittivity, can be seen in Eqs. 3 and 4, respectively. In Eq. 4, $\sigma$ is the electrical conductivity, $\varepsilon$ is the dielectric constant, $j=\sqrt{-1}$, and $i$ serves as an index. The frequencydependent nature of the $\mathrm{CM}$ factor is an interesting tunable 
Fig. 6 Dielectrophoretic (DEP) separation can be a positive (pDEP) or $\mathbf{b}$ negative (nDEP) which affects where cells are positioned within a field. c DEP has been utilized in microfluidic systems in a variety of arrangements, some of which are depicted here a

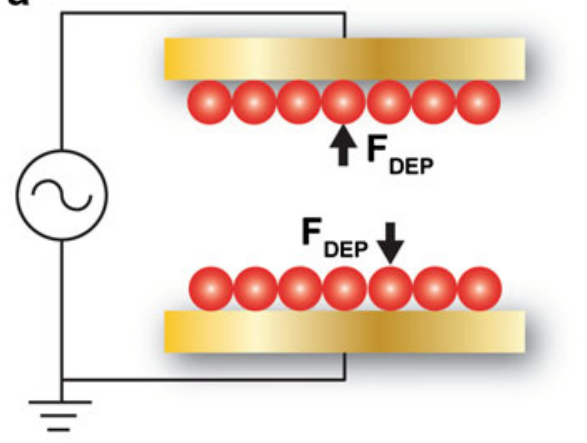

b

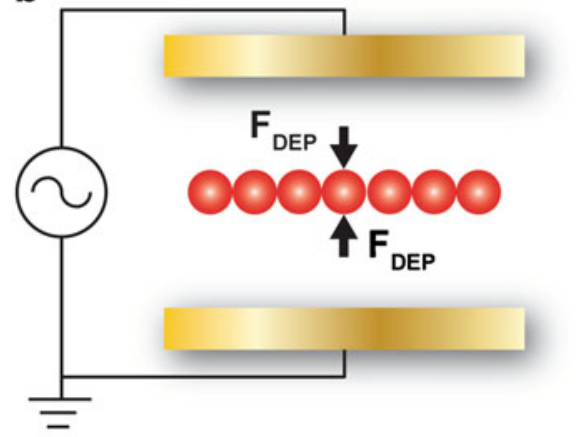

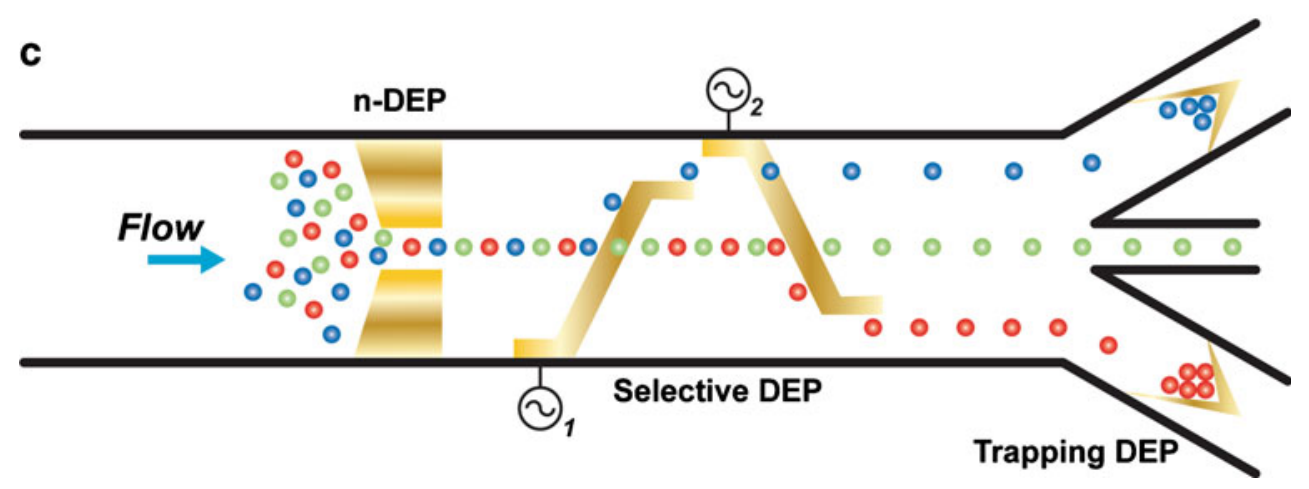

parameter to adjust, as signal frequency is an easily varied parameter in most cases. This enables separation based on two intrinsic properties: frequency and size. When considering cells as the particle being manipulated, it is reasonable that the biological state may contribute to (or even dominate) these frequency-dependent responses. Large, multimeric charged protein complexes, along with complex, dynamic ion gradients across both the cell membrane and internal organelle structures, such as the mitochondrial network, could feasibly have a prominent impact on the ability of a cell to respond to a varying electric field. As mentioned hereafter, it has been shown that live and dead cells of the same cell type have been shown to exhibit differing DEP characteristics, suggesting this hypothesis may hold true; however, it is still unclear the mechanism(s) by which the biological state is acting [98].

$f_{C M}=\frac{\varepsilon_{p}^{*}(\omega)-\varepsilon_{m}^{*}(\omega)}{\varepsilon_{p}^{*}(\omega)+2 \varepsilon_{m}^{*}(\omega)}$

$\varepsilon_{i}^{*}=\varepsilon_{i}-j \frac{\sigma}{\omega}$

The abundance of tunable factors, all contributing to this resultant dielectrophoretic force field, allow for many types of DEP devices, which perform the sorting of heterogeneous populations of particles based on the intrinsic properties of (1) difference in polarizability between the particle and the surrounding medium and (2) the size of the suspended particle. Some commonly manipulated aspects of the DEP force field are the type of driving current (AC or $\mathrm{DC}$ ), the electrode geometry, and the multifaceted $\mathrm{CM}$ factor. There exist advantages and disadvantages to $\mathrm{AC}$ and DC driving currents. Using an AC driving current enables the manipulation of the $\mathrm{CM}$ frequency dependence. DC current, on the other hand, allows for simplicity of device design by not requiring auxiliary equipment other than a voltage source. One significant disadvantage of DC current is the resulting electrochemical reactions on the electrode surface. These redox reactions result in a number of problems, most significantly convective flow, which can counteract particle trapping, and free radical generation that results in significant cellular damage [99].

The electrode geometry has been shown to be important, due to the effect on electric field non-uniformity, both through theoretical models and experimental results. Among others, Green et al. have characterized two common types of electrode designs, specifically in relation to submicrometer particles [100]; however, these designs are also seen in micron-sized manipulation. Two often-used and effective electrode designs are the square $2 \times 2$ array, often used in trapping applications, and the "castellated" electrode design, resembling straight, parallel electrodes with short projections orthogonal to the long axis.

The manipulation of the $\mathrm{CM}$ factor introduces many important design parameters for DEP, namely the frequency of a driving AC signal. The magnitude and sign of the induced dipole moment, a function of the $\mathrm{CM}$ factor, is a crucial factor in design. If the complex permittivity of the particle is greater than that of the medium, then the $\mathrm{CM}$ 
factor is positive and the particle feels a force directed toward the field maximums, termed positive DEP (pDEP), and vice versa (negative, $\mathrm{nDEP}$ ). Particles exhibit positive $\mathrm{CM}$ factors in some ranges of frequency, and negative $\mathrm{CM}$ factors in other distinctly different frequency ranges. The frequency at which the $\mathrm{CM}$ factor is 0 is called the crossover frequency, and the limits of the real part of the $\mathrm{CM}$ factor are considered to be between -0.5 and 1 [101]. These types of DEP can be used to separate heterogeneous colloidal solutions based on where the crossover frequencies lie in frequency space. The imaginary component of the $\mathrm{CM}$ factor is acted upon by traveling waves, and will be explained in more detail in subsequent sections.

DEP electrode setups are frequently fabricated as integrated aspects of a microfluidic channel. The small length scales allow for highly defined non-uniform electric fields, thus more proficient use of the abilities of DEP. In many cases, the microfluidic flow of the DEP device is used only as a means to pass the particle-containing solution over the electrode surfaces. Gagnon et al. used a long, serpentine electrode design to capture and concentrate E. coli using nDEP [102]. The long serpentine design was proposed to reduce faradic reactions on the electrode surface, avoiding electrochemical flow, electrolysis of water, and free radical generation. In order to bring down the crossover frequency of the system, a zwitterionic small molecule (6-aminohexanioc acid) was added to raise the complex permittivity of the medium, as shown previously by Zimmerman et al. [103].

Recently, exciting advances toward the creation of a truly integrated DEP microfluidic system have been made. By stringent design of the electrode geometry, a precise manipulation of DEP forces and fluid forces and their relation has been achieved. DEP gates are an effective and creative method of selecting between multiple types of suspended particles entrained in fluid flow. Chen et al. [104] have shown an analytical solution to the DEP forces in a DEP gate, consisting of two paired electrodes aligned vertically, on the top and bottom wall of the channel. Experimentally, they also were able to accomplish separation between $4.8-$ and $8-\mu \mathrm{m}$ beads at a flow rate of $2 \mu \mathrm{L} /$ min with up to $98 \%$ purity [104].

Cheng et al. have demonstrated the ability not only to select between bacteria by their crossover frequencies, but also to trap these separated bacterial solutions downstream for analysis [105]. The design of the DEP gates were optimized based on average fluid velocity, taking advantage of a force balance between Stokes drag and DEP force. They have shown that an 'arrowhead' trap shape was optimal due to the sharp corner in the center of the channel, allowing for high local field gradients and effective trapping in particular flow up to $1.25 \mathrm{~mm} / \mathrm{s}$, corresponding to volumetric flow of $2 \mu \mathrm{L} / \mathrm{min}$ [105]. The combination of both label-free separation and trapping is an example of what can be accomplished by truly integrating DEP forces and fluid forces.

Altering the driving signal to the electrodes enables a new method of distinguishing between particles other than the crossover frequency. Recently, Cui et al. [106] characterized and demonstrated, what they term, pulsed DEP. This method makes use of a complex driving signal: a sinusoid multiplied with a square wave of frequency $10 \mathrm{~Hz}$ and $50 \%$ duty cycle. In this method, the frequency of the sinusoid wave is held constant, and particles can be selected based on size by changing the frequency of the square wave using a simple electrode design [106]. This technique operates at a flow rate of only $0.8 \mu \mathrm{L} / \mathrm{min}$; however, it is capable of separating either 3-, 5-, or 10- $\mu \mathrm{m}$ particles from a mixture, just by tuning the frequency of the applied square wave, illustrating the ease of multiplexing. The authors also suggest the ability to increase the flow rate with higher voltage and frequencies.

One drawback to DEP chips is the slight difficulty in fabrication, especially aligning gate electrodes. Cummings et al. [107] proposed a simple and robust method to circumvent this impediment. Rather than patterning conductive electrodes on the device, they pattern insulating posts of varying designs in the channel. This allows for remote electrode placement, as the special non-uniformities in the electric field are resultant from the insulating boundaries, with operation down to frequencies that would normally cause detrimental reactions. In this form of DEP fluid flow is resultant from electroosmosis, which restricts the flow rate [107]; however, this technique has demonstrated the ability to create ordered streams and separate particles from suspension.

Recently, Vahey et al. [98] have shown a true integration of microfluidic fluid flow, convection and diffusion, and DEP force fields producing a passive separator. The device consists of an inlet diffusive mixer, common to microfluidic devices, coupled with a long straight channel with angled electrodes running the diagonal of the long channel. The diffusive mixer results in a gradient of conductivity across the short dimension of the channel spanning 9.3 to $47 \mathrm{mS} /$ $\mathrm{m}$. At a flow rate of $3 \mu \mathrm{L} / \mathrm{min}$, a mixture of live and dead $S$. cervisea were separated into parallel streams as measured by fluorescence intensity profiles [98]. This separation, based on differences in membrane permeabilites (as in the case of live versus dead cells), is a feat thus far unmatched by many other techniques.

Another important development in DEP is the advent of traveling wave DEP (twDEP). Briefly, twDEP makes use of the imaginary component of the $\mathrm{CM}$ factor. Numerous theoretical models of twDEP force fields have been created by using numerical simulation [108], Fourier series [109], Green's functions and theorem [110], and more recently the 
Schwarz-Christoffel mapping (SCM) method [111]. These have shown that twDEP makes use of the imaginary component of the CM factor and, furthermore, that the real and imaginary components of the CM factor are acted upon independently by the electric field and correspond to trapping and translational forces, respectively.

This wealth of theoretical information has allowed successful creation of separation devices based on twDEP. Cheng et al. have created a simple two-module DEP device consisting of an initial focusing region using DEP, followed by an array of twDEP electrodes running along the longitudinal axis of flow. Using this design, Cheng et al. separated and qualitatively characterized $S$. aureus and RBCs at a flow rate of $4 \mu \mathrm{L} / \mathrm{min}$, whereas a polydisperse mixture of liposomes ranging from about $100 \mathrm{~nm}$ to $3 \mu \mathrm{m}$ were sorted at a flow rate of $6 \mu \mathrm{L} / \mathrm{min}$, and quantitatively characterized by fluorescence intensity measurements [112].

These innovations of late have created new possibilities for the label-free separation and sorting abilities of DEP. The integration of microfluidic force fields and DEP fields has allowed for creative solutions for label-free applications. Presently, the state of these integrated, multi-module devices is promising. The highest throughputs of DEP $(<6 \mu \mathrm{L} / \mathrm{min})$ are still low in comparison with some other technologies; however, the basis on which separation is made places DEP in a potentially very useful niche. Separating based on electrical characteristics (specifically the polarizability) allows for distinguishing between live and dead cells, as well as types of bacteria by physical properties other than just size. In order for this technology to become truly useful and accessible, it is necessary to create large, thorough libraries of characteristic DEP data, such as crossover frequencies. Some of the experiments have been done, among them an analysis of how gene expression profiles are affected by DEP [113], characterization of the crossover frequencies of all mononuclear components of blood [114], linking how biological states, such as RBC starvation and glutaraldehyde cross-linking, lead to changes in crossover frequencies [115], and mapping lateral displacement as a function of particle size in specific general electrode designs [116].

\section{Optical (refractive index, size)}

Optical techniques for manipulating particles have recently been developed into effective platforms for the sorting of heterogeneous populations. Chiou et al. developed a novel platform by which DEP electrodes could be optically patterned in real time using a low intensity light source and a large field of view objective. These mobile electrodes were used in a virtual optical machine for size-exclusion separation. Furthermore, live and dead B cells were separated by using an 'optoelectronic tweezers' (OET) pattern of concentric circles, which impart a negative 'trapping' force on live cells, directing them toward the center of the circles [117]. OET has been further improved by creating dynamic OET patterns such as scanning electrode lines moving orthogonal to its long axis. Using this design, Chiou et al. separated a suspension of HeLa (cervical carcinoma) and Jurkat (acute $\mathrm{T}$ cell leukemia) cells, based on polarizability and size, where HeLa cells are about twice as large as Jurkats. This work also characterized the relationship between applied signal frequency and the resultant velocity, clearly showing an optimal frequency range for separation [118]. While these techniques may be useful in analytical tools, they have not been demonstrated in continuous systems for processing large samples. In the direction of designing analytical tools, OET, specifically lateral field OET (LOET), has been integrated into electrowetting on dielectric (EWOD) systems in order to automate the separation of cell suspensions. Shah et al. have demonstrated the automated concentration of HeLa cells into droplets via EWOD-LOET [119].

Passive, optical techniques have been developed for continuous separation in flow. Macdonald et al. demonstrated the sorting of silica and polymer beads by their differences in optical diffraction, with an efficiency greater than $96 \%$. A suspension of 2 - and $4-\mu \mathrm{m}$ protein microcapsules were also separated by size and qualitatively analyzed [120]. This technique, unlike DLD, does not divert fluid flow, only the particles traveling in the flow feel an applied force, presumably based on the refractive index of the particle, which is related to the permittivity. It is interesting to note that a cell, with multiple complex membrane structures, organelles, and macromolecules, can potentially have significantly different refractive indexes based on their biological states. Milne et al. [121] created a more highly resolved size separation microfluidic system capable of segregating in flow as many as four sizes of silica spheres with diameter differences as small as $0.54 \mu \mathrm{m}$ with a throughput of 40 particles per second [121]. These optical techniques have shown promise in terms of separating polymer particles, and some protein colloids; however, the separation of intact cells remains to be fully demonstrated. In the literature to date, there are no successful demonstrations of cell separation. This is presumably due to low efficiencies of separation, perhaps because of little understanding of the mechanisms by which these optical separations act. It remains to be shown that optical techniques are a viable method of cell separation.

\section{Outlook}

Label-free separation and sorting techniques face many hurdles to widespread adoption. While conventional tech- 
niques have drawbacks, they are reliable and robust and it will be difficult to supplant the notion that antibody-based selection is the most ideal. Selectivity of label-free techniques may be considered low when they depend on only one biomarker. Combinatorial techniques may offer more accurate separation. Thus, success of the technologies reviewed here hinges on development of accurate physical biomarker profiles which vary with cell phenotype. Furthermore, accurate and thorough reporting of separation performance metrics as they relate to specific applications is imperative. We encountered many challenges in assembling a comparative table of these metrics from the literature. While some of these have be due to the wide range of sorting applications that have been approached, a large number may be attributed to a lack of clarity when describing how one came upon values of efficiency, purity, enrichment, throughput, etc. The reporting of these numbers is nontrivial and accompanying equations should be provided.

Open Access This article is distributed under the terms of the Creative Commons Attribution Noncommercial License which permits any noncommercial use, distribution, and reproduction in any medium, provided the original author(s) and source are credited.

\section{References}

1. Li J, Zhang Z, Rosenzweig J, Wang YY, Chan DW (2002) Proteomics and bioinformatics approaches for identification of serum biomarkers to detect breast cancer. Clin Chem 48:12961304

2. Villanueva J, Shaffer DR, Philip J, Chaparro CA, ErdjumentBromage H, Olshen AB, Fleisher M, Lilja H, Brogi E, Boyd J, Sanchez-Carbayo M, Holland EC, Cordon-Cardo C, Scher HI, Tempst P (2006) Differential exoprotease activities confer tumorspecific serum peptidome patterns. J Clin Invest 116:271-284

3. Bunn HF (1997) Pathogenesis and treatment of sickle cell disease. N Engl J Med 337:762-769

4. Toner M, Irimia D (2005) Blood-on-a-chip. Annu Rev Biomed Eng 7:77-103

5. Cristofanilli M, Budd GT, Ellis MJ, Stopeck A, Matera J, Miller MC, Reuben JM, Doyle GV, Allard WJ, Terstappen LW, Hayes DF (2004) Circulating tumor cells, disease progression, and survival in metastatic breast cancer. N Engl J Med 351:781791

6. Krabchi K, Gros-Louis F, Yan J, Bronsard M, Massé J, Forest JC, Drouin R (2001) Quantification of all fetal nucleated cells in maternal blood between the 18th and 22nd weeks of pregnancy using molecular cytogenetic techniques. Clin Genet 60:145150

7. Sethu P, Sin A, Toner M (2006) Microfluidic diffusive filter for apheresis (leukapheresis). Lab Chip 6:83-89

8. Roda B, Reschiglian P, Zattoni A, Alviano F, Lanzoni G, Costa R, Di Carlo AD, Marchionni C, Franchina M, Bonsi L, Bagnara GP (2009) A tag-less method of sorting stem cells from clinical specimens and separating mesenchymal from epithelial progenitor cells. Cytometry B Clin Cytom 76B:285-290
9. Choi S, Song S, Choi C, Park J (2009) Microfluidic self-sorting of mammalian cells to achieve cell cycle synchrony by hydrophoresis. Anal Chem 81:1964-1968

10. El-Ali J, Sorger PK, Jensen KF (2006) Cells on chips. Nature 442:403-411

11. Shapiro HM (2003) Practical flow cytometry. Wiley-Liss, New York

12. Miltenyi S, Müller W, Weichel W, Radbruch A (1990) High gradient magnetic cell separation with MACS. Cytometry $11: 231-238$

13. Després D, Flohr T, Uppenkamp M, Baldus M, Hoffmann M, Huber C, Derigs HG (2000) CD34+ cell enrichment for autologous peripheral blood stem cell transplantation by use of the CliniMACs device. J Hematother Stem Cell Res 9:557-564

14. Allan AL, Vantyghem SA, Tuck AB, Chambers AF, Chin-Yee IH, Keeney M (2005) Detection and quantification of circulating tumor cells in mouse models of human breast cancer using immunomagnetic enrichment and multiparameter flow cytometry. Cytometry A 65:4-14

15. Hager G, Tong DC, Schiebel I, Rezniczek GA, Watrowski R, Speiser P, Zeillinger R (2005) The use of a panel of monoclonal antibodies to enrich circulating breast cancer cells facilitates their detection. Gynecol Oncol 98:211-216

16. Kumar A, Bhardwaj A (2008) Methods in cell separation for biomedical application: cryogels as a new tool. Biomed Mater 3:034008

17. English D, Andersen BR (1974) Single-step separation of red blood cells, granulocytes and mononuclear leukocytes on discontinuous density gradients of Ficoll-Hypaque. J Immunol Methods 5:249-252

18. Lundahl J, Halldén G, Hallgren M, Sköld CM, Hed J (1995) Altered expression of CD11b/CD18 and CD62L on human monocytes after cell preparation procedures. J Immunol Methods 180:93-100

19. Fukuda S, Schmid-Schonbein GW (2002) Centrifugation attenuates the fluid shear response of circulating leukocytes. J Leukoc Biol 72:133-139

20. SooHoo J, Walker G (2009) Microfluidic aqueous two phase system for leukocyte concentration from whole blood. Biomed Microdevices 11:323-329

21. Sollier E, Rostaing H, Pouteau P, Fouillet Y, Achard J (2009) Chemical: passive microfluidic devices for plasma extraction from whole human blood. Sens Actuators B Chem 141:617-624

22. Whitesides GM (2006) The origins and the future of microfluidics. Nature 442:368-373

23. Squires TM, Quake SR (2005) Microfluidics: fluid physics at the nanoliter scale. Rev Mod Phys 77:977

24. Pamme N (2007) Continuous flow separations in microfluidic devices. Lab Chip 7:1644-1659

25. Tsutsui H, Ho C (2009) Cell separation by non-inertial force fields in microfluidic systems. Mech Res Commun 36:92-103

26. Chen P, Feng X, Du W, Liu B (2008) Microfluidic chips for cell sorting. Front Biosci 13:2464-2483

27. Lenshof A, Laurell T (2010) Continuous separation of cells and particles in microfluidic systems. Chem Soc Rev 39:1203-1217

28. Ji H, Samper V, Chen Y, Heng C, Lim T, Yobas L (2008) Silicon-based microfilters for whole blood cell separation. Biomed Microdevices 10:251-257

29. Brody JP, Osborn TD, Forster FK, Yager P (1996) A planar microfabricated fluid filter. Sens Actuators A Phys 54:704-708

30. Crowley TA, Pizziconi V (2005) Isolation of plasma from whole blood using planar microfilters for lab-on-a-chip applications. Lab Chip 5:922-929

31. VanDelinder V, Groisman A (2006) Separation of plasma from whole human blood in a continuous cross-flow in a molded microfluidic device. Anal Chem 78:3765-3771 
32. Chen X, Cui DF, Liu CC, Li H (2008) Microfluidic chip for blood cell separation and collection based on crossflow filtration. Sens Actuators B Chem 130:216-221

33. Mohamed H, Turner JN, Caggana M (2007) Biochip for separating fetal cells from maternal circulation. J Chromatogr A $1162: 187-192$

34. Jönsson C, Aronsson M, Rundström G, Pettersson C, MendelHartvig I, Bakker J, Martinsson E, Liedberg B, MacCraith B, Öhman O, Melin J (2008) Silane-dextran chemistry on lateral flow polymer chips for immunoassays. Lab Chip 8:1191

35. Chen X, Cui D, Zhang L (2009) Isolation of plasma from whole blood using a microfludic chip in a continuous cross-flow. Chin Sci Bull 54:324-327

36. Sethu P, Sin A, Toner M (2006) Microfluidic diffusive filter for apheresis (leukapheresis). Lab Chip 6:83-89

37. VanDelinder V, Groisman A (2007) Perfusion in microfluidic cross-flow: separation of white blood cells from whole blood and exchange of medium in a continuous flow. Anal Chem 79:20232030

38. Murthy S, Sethu P, Vunjak-Novakovic G, Toner M, Radisic M (2006) Size-based microfluidic enrichment of neonatal rat cardiac cell populations. Biomed Microdevices 8:231-237

39. Chen X, Cui D, Liu C, Li H, Chen J (2007) Continuous flow microfluidic device for cell separation, cell lysis and DNA purification. Anal Chim Acta 584:237-243

40. Zheng S, Lin H, Liu J, Balic M, Datar R, Cote RJ, Tai Y (2007) Membrane microfilter device for selective capture, electrolysis and genomic analysis of human circulating tumor cells. J Chromatogr A 1162:154-161

41. Kuo JS, Zhao Y, Schiro PG, Ng L, Lim DSW, Shelby JP, Chiu DT (2010) Deformability considerations in filtration of biological cells. Lab Chip. doi:10.1039/b922301k

42. Yamada M, Nakashima M, Seki M (2004) Pinched flow fractionation: continuous size separation of particles utilizing a laminar flow profile in a pinched microchannel. Anal Chem 76:5465-5471

43. Takagi J, Yamada M, Yasuda M, Seki M (2005) Continuous particle separation in a microchannel having asymmetrically arranged multiple branches. Lab Chip 5:778

44. Yamada M, Seki M (2005) Hydrodynamic filtration for on-chip particle concentration and classification utilizing microfluidics. Lab Chip 5:1233-1239

45. Yamada M, Kano K, Tsuda Y, Kobayashi J, Yamato M, Seki M, Okano T (2007) Microfluidic devices for size-dependent separation of liver cells. Biomed Microdevices 9:637-645

46. Huang LR, Cox EC, Austin RH, Sturm JC (2004) Continuous particle separation through deterministic lateral displacement. Science 304:987-990

47. Inglis DW, Davis JA, Austin RH, Sturm JC (2006) Critical particle size for fractionation by deterministic lateral displacement. Lab Chip 6:655-658

48. Zheng S, Tai Y, Kasdan H (2005) A micro device for separation of erythrocytes and leukocytes in human blood. Conf Proc IEEE Eng Med Biol Soc 1:1024-1027

49. Davis JA, Inglis DW, Morton KJ, Lawrence DA, Huang LR, Chou SY, Sturm JC, Austin RH (2006) Deterministic hydrodynamics: taking blood apart. Proc Natl Acad Sci U S A 103:14779-14784

50. Inglis DW, Davis JA, Zieziulewicz TJ, Lawrence DA, Austin RH, Sturm JC (2008) Determining blood cell size using microfluidic hydrodynamics. J Immunol Methods 329:151-156

51. Morton KJ, Loutherback K, Inglis DW, Tsui OK, Sturm JC, Chou SY, Austin RH (2008) Crossing microfluidic streamlines to lyse, label and wash cells. Lab Chip 8:1448-1453

52. Inglis DW (2009) Efficient microfluidic particle separation arrays. Appl Phys Lett 94:013510-013513
53. Long BR, Heller M, Beech JP, Linke H, Bruus H, Tegenfeldt JO (2008) Multidirectional sorting modes in deterministic lateral displacement devices. Phys Rev E 78:046304-046309

54. Huang R, Barber TA, Schmidt MA, Tompkins RG, Toner M, Bianchi DW, Kapur R, Flejter WL (2008) A microfluidics approach for the isolation of nucleated red blood cells (NRBCs) from the peripheral blood of pregnant women. Prenat Diagn 28:892-899

55. Giddings JC (1993) Field-flow fractionation: analysis of macromolecular, colloidal, and particulate materials. Science 260:1456-1465

56. Giddings JC (1985) A System based on split-flow lateraltransport thin (splitt) separation cells for rapid and continuous particle fractionation. Sep Sci Technol 20:749

57. Vykoukal J, Vykoukal DM, Freyberg S, Alt EU, Gascoyne PRC (2008) Enrichment of putative stem cells from adipose tissue using dielectrophoretic field-flow fractionation. Lab Chip 8:1386-1393

58. Roda B, Zattoni A, Reschiglian P, Moon MH, Mirasoli M, Michelini E, Roda A (2009) Field-flow fractionation in bioanalysis: a review of recent trends. Anal Chim Acta 635:132-143

59. Howell PB Jr, Mott DR, Fertig S, Kaplan CR, Golden JP, Oran ES, Ligler FS (2005) A microfluidic mixer with grooves placed on the top and bottom of the channel. Lab Chip 5:524

60. Lynn NS, Dandy DS (2007) Geometrical optimization of helical flow in grooved micromixers. Lab Chip 7:580-587

61. Choi S, Park J (2007) Continuous hydrophoretic separation and sizing of microparticles using slanted obstacles in a microchannel. Lab Chip 7:890-897

62. Hsu C, Di Carlo D, Chen C, Irimia D, Toner M (2008) Microvortex for focusing, guiding and sorting of particles. Lab Chip 8:2128-2134

63. Di Carlo D (2009) Inertial microfluidics. Lab Chip 9:3038-3046

64. Segré G, Silberberg A (1961) Radial particle displacements in poiseuille flow of suspensions. Nature 189:209-210

65. Di Carlo D, Irimia D, Tompkins RG, Toner M (2007) Continuous inertial focusing, ordering, and separation of particles in microchannels. Proc Natl Acad Sci U S A 104:18892-18897

66. Gossett DR, Di Carlo D (2009) Particle focusing mechanisms in curving confined flows. Anal Chem 81:8459-8465

67. Berger SA, Talbot L, Yao LS (1983) Flow in curved pipes. Ann Rev Fluid Mech 15:461-512

68. Sudarsan AP, Ugaz VM (2006) Multivortex micromixing. Proc Natl Acad Sci U S A 103:7228-7233

69. Seo J, Lean MH, Kole A (2007) Membrane-free microfiltration by asymmetric inertial migration. Appl Phys Lett 91:033901033903

70. Di Carlo D, Edd JF, Irimia D, Tompkins RG, Toner M (2008) Equilibrium separation and filtration of particles using differential inertial focusing. Anal Chem 80:2204-2211

71. Kuntaegowdanahalli SS, Bhagat AAS, Kumar G, Papautsky I (2009) Inertial microfluidics for continuous particle separation in spiral microchannels. Lab Chip 9:2973-2980

72. Wu Z, Willing B, Bjerketorp J, Jansson JK, Hjort K (2009) Soft inertial microfluidics for high throughput separation of bacteria from human blood cells. Lab Chip 9:1193-1199

73. Hur SC, Tse HTK, Di Carlo D (2010) Sheathless inertial cell ordering for extreme throughput flow cytometry. Lab Chip 10:274 280

74. Huh D, Bahng JH, Ling Y, Wei H, Kripfgans OD, Fowlkes JB, Grotberg JB, Takayama S (2007) Gravity-driven microfluidic particle sorting device with hydrodynamic separation amplification. Anal Chem 79:1369-1376

75. Shevkoplyas SS, Yoshida T, Munn LL, Bitensky MW (2005) Biomimetic autoseparation of leukocytes from whole blood in a microfluidic device. Anal Chem 77:933-937 
76. Jäggi RD, Sandoz R, Effenhauser CS (2006) Microfluidic depletion of red blood cells from whole blood in high-aspectratio microchannels. Microfluid Nanofluid 3:47-53

77. Faivre M, Abkarian M, Bickraj K, Stone HA (2006) Geometrical focusing of cells in a microfluidic device: an approach to separate blood plasma. Biorheology 43:147-159

78. Yang S, Undar A, Zahn JD (2006) A microfluidic device for continuous, real time blood plasma separation. Lab Chip 6:871

79. Zborowski M, Ostera GR, Moore LR, Milliron S, Chalmers JJ, Schechter AN (2003) Red blood cell magnetophoresis. Biophys J 84:2638-2645

80. Han K, Frazier AB (2004) Continuous magnetophoretic separation of blood cells in microdevice format. J Appl Phys 96:5797-5802

81. Han K, Frazier AB (2005) Diamagnetic capture mode magnetophoretic microseparator for blood cells. J Microelectromech Syst 14:1422-1431

82. Han K, Frazier AB (2006) Paramagnetic capture mode magnetophoretic microseparator for high efficiency blood cell separations. Lab Chip 6:265-273

83. Furlani EP (2007) Magnetophoretic separation of blood cells at the microscale. J Phys D Appl Phys 40:1313-1319

84. Jung J, Han K (2008) Lateral-driven continuous magnetophoretic separation of blood cells. Appl Phys Lett 93:223902-223903

85. Yamada M, Kasim V, Nakashima M, Edahiro J, Seki M (2004) Continuous cell partitioning using an aqueous two-phase flow system in microfluidic devices. Biotechnol Bioeng 88:489-494

86. Nam K, Chang W, Hong H, Lim S, Kim D, Koo Y (2005) Continuous-flow fractionation of animal cells in microfluidic device using aqueous two-phase extraction. Biomed Microdevices 7:189-195

87. Wiklund M, Hertz HM (2006) Ultrasonic enhancement of beadbased bioaffinity assays. Lab Chip 6:1279-1292

88. Laurell T, Petersson F, Nilsson A (2007) Chip integrated strategies for acoustic separation and manipulation of cells and particles. Chem Soc Rev 36:492-506

89. Petersson F, Nilsson A, Holm C, Jonsson H, Laurell T (2005) Continuous separation of lipid particles from erythrocytes by means of laminar flow and acoustic standing wave forces. Lab Chip 5:20 22

90. Petersson F, Nilsson A, Holm C, Jonsson H, Laurell T (2004) Separation of lipids from blood utilizing ultrasonic standing waves in microfluidic channels. Analyst 129:938-943

91. Lenshof A, Ahmad-Tajudin A, Jaras K, Sward-Nilsson A, Aberg L, Marko-Varga G, Malm J, Lilja H, Laurell T (2009) Acoustic whole blood plasmapheresis chip for prostate specific antigen microarray diagnostics. Anal Chem 81:6030-6037

92. Kapishnikov S, Kantsler V, Steinberg V (2006) Continuous particle size separation and size sorting using ultrasound in a microchannel. J Stat Mech Theory Exp 2006:P01012

93. Hawkes JJ, Coakley WT (2001) Force field particle filter, combining ultrasound standing waves and laminar flow. Sens Actuators B Chem 75:213-222

94. Gupta S, Feke DL, Manas-Zloczower I (1995) Fractionation of mixed particulate solids according to compressibility using ultrasonic standing wave fields. Chem Eng Sci 50:3275-3284

95. Petersson F, Aberg L, Sward-Nilsson A, Laurell T (2007) Free flow acoustophoresis: microfluidic-based mode of particle and cell separation. Anal Chem 79:5117-5123

96. Wang X, Huang Y, Becker FF, Gascoyne PRC (1994) A unified theory of dielectrophoresis and travelling wave dielectrophoresis. J Phys D Appl Phys 27:1571-1574

97. Gascoyne PRC, Vykoukal J (2002) Particle separation by dielectrophoresis. Electrophoresis 23:1973-1983

98. Vahey MD, Voldman J (2008) An equilibrium method for continuous-flow cell sorting using dielectrophoresis. Anal Chem $80: 3135-3143$
99. Wang X, Yang J, Gascoyne PRC (1999) Role of peroxide in AC electrical field exposure effects on Friend murine erythroleukemia cells during dielectrophoretic manipulations. Biochim Biophys Acta 1426:53-68

100. Green NG, Ramos A, Morgan H (2000) Ac electrokinetics: a survey of sub-micrometre particle dynamics. J Phys D Appl Phys 33:632-641

101. Ramos A, Morgan H, Green NG, Castellanos A (1998) Ac electrokinetics: a review of forces in microelectrode structures. J Phys D Appl Phys 31:2338-2353

102. Gagnon Z, Chang H (2005) Aligning fast alternating current electroosmotic flow fields and characteristic frequencies with dielectrophoretic traps to achieve rapid bacteria detection. Electrophoresis 26:3725-3737

103. Arnold WM, Schwan HP, Zimmermann U (1987) Surface conductance and other properties of latex particles measured by electrorotation. J Phys Chem 91:5093-5098

104. Chen DF, Du H, Li WH (2006) A 3D paired microelectrode array for accumulation and separation of microparticles. J Micromech Microeng 16:1162-1169

105. Cheng I, Chang H, Hou D, Chang H (2007) An integrated dielectrophoretic chip for continuous bioparticle filtering, focusing, sorting, trapping, and detecting. Biomicrofluidics 1:021503

106. Cui H, Voldman J, He X, Lim K (2009) Separation of particles by pulsed dielectrophoresis. Lab Chip 9:2306-2312

107. Cummings EB, Singh AK (2003) Dielectrophoresis in microchips containing arrays of insulating posts: theoretical and experimental results. Anal Chem 75:4724-4731

108. Hughes MP, Pethig R, Wang X (1996) Dielectrophoretic forces on particles in travelling electric fields. J Phys D Appl Phys 29:474-482

109. Morgan H, Izquierdo AG, Bakewell D, Green NG, Ramos A (2001) The dielectrophoretic and travelling wave forces generated by interdigitated electrode arrays: analytical solution using Fourier series. J Phys D Appl Phys 34:1553-1561

110. Liang E, Smith RL, Clague DS (2004) Dielectrophoretic manipulation of finite sized species and the importance of the quadrupolar contribution. Phys Rev E 70:066617

111. Sun T, Morgan H, Green NG (2007) Analytical solutions of ac electrokinetics in interdigitated electrode arrays: electric field, dielectrophoretic and traveling-wave dielectrophoretic forces. Phys Rev E 76:046610-046618

112. Cheng I, Froude VE, Zhu Y, Chang H, Chang H (2009) A continuous high-throughput bioparticle sorter based on 3D traveling-wave dielectrophoresis. Lab Chip 9:3193-3201

113. Huang Y, Joo S, Duhon M, Heller M, Wallace B, Xu X (2002) Dielectrophoretic cell separation and gene expression profiling on microelectronic chip arrays. Anal Chem 74:3362-3371

114. Vykoukal DM, Gascoyne PRC, Vykoukal J (2009) Dielectric characterization of complete mononuclear and polymorphonuclear blood cell subpopulations for label-free discrimination. Integr Biol 1:477-484

115. Gordon JE, Gagnon Z, Chang H (2007) Dielectrophoretic discrimination of bovine red blood cell starvation age by buffer selection and membrane cross-linking. Biomicrofluidics 1:044102044105

116. Han K, Han S, Frazier AB (2009) Lateral displacement as a function of particle size using a piecewise curved planar interdigitated electrode array. Lab Chip 9:2958-2964

117. Chiou PY, Ohta AT, Wu MC (2005) Massively parallel manipulation of single cells and microparticles using optical images. Nature 436:370-372

118. Ohta A, Chiou P, Phan H, Sherwood S, Yang J, Lau A, Hsu H, Jamshidi A, Wu M (2007) Optically controlled cell discrimination and trapping using optoelectronic tweezers. IEEE J Sel Top Quantum Electron 13:235-243 
119. Shah GJ, Ohta AT, Chiou EP, Wu MC, Kim C (2009) EWODdriven droplet microfluidic device integrated with optoelectronic tweezers as an automated platform for cellular isolation and analysis. Lab Chip 9:1732-1739

120. MacDonald MP, Spalding GC, Dholakia K (2003) Microfluidic sorting in an optical lattice. Nature 426:421-424
121. Milne G, Rhodes D, MacDonald M, Dholakia K (2007) Fractionation of polydisperse colloid with acousto-optically generated potential energy landscapes. Opt Lett 32:11441146

122. Choi S, Song S, Choi C, Park J (2007) Continuous blood cell separation by hydrophoretic filtration. Lab Chip 7:1532-1538 